\title{
Biologie statistique / Statistical biology
}

Centre interdisciplinaire de recherche en biologie (CIRB)

\section{Olivier Rivoire}

\section{(2) OpenEdition}

\section{Journals}

Édition électronique

URL : https://journals.openedition.org/annuaire-cdf/16149

DOI : 10.4000/annuaire-cdf. 16149

ISBN : 978-2-7226-0572-5

ISSN : 2109-9227

Éditeur

Collège de France

\section{Édition imprimée}

Date de publication : 30 décembre 2020

Pagination : 661

ISBN : 978-2-7226-0516-9

ISSN : 0069-5580

\section{Référence électronique}

Olivier Rivoire, "Biologie statistique / Statistical biology », L'annuaire du Collège de France [En ligne], 118 | 2020, mis en ligne le 01 avril 2021, consulté le 22 août 2022. URL : http://journals.openedition.org/ annuaire-cdf/16149; DOI : https://doi.org/10.4000/annuaire-cdf.16149 


\title{
BIOlOgie STATISTIQUe / Statistical BIOLOGY
}

\author{
Responsable : Olivier RIVOIRE
}

\section{RECHERCHE}

Page web : https://www.college-de-france.fr/site/en-cirb/rivoire.htm.

Notre équipe cherche à comprendre les principes sous-jacents aux capacités d'adaptation des systèmes biologiques. Notre approche est inspirée de la physique statistique et combine des analyses de séquences génomiques, des expériences quantitatives in vitro et des modèles mathématiques. Nos projets actuels sont organisés autour de trois systèmes modèles: les anticorps, les protéases et les génomes bactériens.

Nos résultats récents comprennent le développement de méthodes statistiques pour étudier la co-évolution dans les séquences de protéines et de génomes, le développement d'expériences d'évolution d'anticorps par la méthode de phage display et le développement de modèles mathématiques d'évolution de populations sujettes à des environnements fluctuants.

\section{PuBLiCATIONS}

Mayer A., Mora T., Rivoire O. et WalczaK A.M., «Transitions in optimal adaptive strategies for populations in fluctuating environments », Physical Review. E, vol. 96, n 3-1, 2017, 032412, DOI : 10.1103/PhysRevE.96.032412.

JUNIER I., FRÉMONT P. et RIVOIRE O., « Universal and idiosyncratic characteristic lengths in bacterial genomes », Physical Biology, vol. 15, nº 3, 2018, 035001, DOI : 10.1088/1478-3975/ aab4ac.

\section{INTERACTIONS NEUROGLIALES EN PHYSIOPATHOLOGIE CÉRÉBRALE / NEUROGLIAL INTERACTIONS IN CEREBRAL PHYSIOPATHOLOGY}

\author{
Responsable : Nathalie ROUACH
}

\section{RECHERCHE}

Page web : https://www.college-de-france.fr/site/en-cirb/rouach.htm.

The main goal of our group is to determine whether and how the underexplored glial cells, which are the very abundant non neuronal but yet active cells of the brain, play a role in brain information processing. We investigate the molecular modalities and functional outcomes of neuroglial interactions in physiological and pathological conditions, focusing ex vivo or in vivo on neuronal excitability, synaptic transmission, plasticity and synchronization, as well as on cognitive functions. To do so, we use a 